\title{
BRASIL, MOSTRA A SUA CARA: APROXIMAÇÕES AO CENÁRIO BRASILEIRO DE DOCUMENTÁRIOS INTERATIVOS
}

\begin{abstract}
André Paz; Julia Salles*
Resumo: Nos últimos anos, surgiu uma ampla e diversa gama de produções internacionais de narrativas interativas não ficcionais, que utilizam mídias digitais e exploram a transversalidade de linguagens e plataformas. Acontecem em um território híbrido, entre reportagem na web, documentário, arte interativa, netart, games, instalação. Têm sido chamadas de webdocumentário, documentário interativo, living documentary. Em parte, essas obras têm sido reconhecidas em festivais internacionais de documentário, como o IDFA, e incorporadas à pesquisa acadêmica em centros de referência internacional, como o MIT Open Documentary Lab. No Brasil, algumas obras surgiram nos últimos anos, mas a produção artística e a pesquisa acadêmica ainda não têm acompanhado esse cenário promissor. Este ensaio apresenta aproximações ao cenário brasileiro contemporâneo de documentários interativos, orientado pela perspectiva de uma estética relacional, que vem sendo desenvolvida pelos autores em um projeto de pesquisa mais amplo sobre o campo.

Palavras-Chaves: documentário interativo, webdocumentário, interatividade.

Resumen: En los últimos años ha surgido una amplia y diversa gama de producciones internacionales de narraciones interactivas no ficcionales que utilizan los medios digitales y exploran la transversalidad de lenguajes y plataformas. Tienen lugar en un territorio híbrido, entre reportaje en la Web, documental, arte interactivo, netart, games e instalación. Se les ha llamado webdocumental, documental interactivo, living documentary. En parte, estas obras han sido reconocidas en festivales internacionales del documental como el IDFA e incorporadas a la investigación académica en centros internacionales de referencia como el MIT Open Documentary Lab. En Brasil, han surgido en los últimos años algunos trabajos, pero la producción artística y la investigación académica aún no han acompañado este escenario prometedor. Este ensayo presenta aproximaciones al escenario brasileño contemporáneo de documentales interactivos, guiado por la perspectiva de una estética relacional que está siendo desarrollada por los autores en un proyecto de investigación más amplio sobre el campo.

Palabras clave: documental interactivo, webdocumental, interactividad.
\end{abstract}

\footnotetext{
* André Paz: Universidade Federal do Estado do Rio de Janeiro - UNIRIO, Pesquisador de Pós Doutorado na Universidade Federal do Rio de Janeiro - UFRJ no Instituto de Letras/Instituto Alberto Luiz Coimbra de Pós-graduação e Pesquisa de Engenharia COPPE, Programa Avançado de Cultura Contemporânea - PACC/Programa de Engenharia de Produção - PEP, 21941-972, Rio de Janeiro, Brasil. E-mail:andredapaz@ gmail.com Julia Salles: Doutoranda. Université du Québec à Montréa - UQÀM, Faculdade de Comunicação, Bolsista do Doutorado pleno da CAPES, Brasil. H3H 2A8, Montréal, Canadá. E-mail: juliacsalles@yahoo.com.br
}

Submissão do artigo: 01 de junho de 2015. Notificação de aceitação: 20 de agosto de 2015. 


\begin{abstract}
In recent years, a series of international productions of interactive nonfictional narratives has developed. They use and explore the transversality of languages and media. These narratives takes place in a hybrid territory between the journalistic webreport, documentary, interactive art, net art, video games, installation. They were called webdocumentary, interactive documentary, living documentary. In part, these works have been recognized in international documentary festivals such as IDFA, and incorporated into academic research by leading research centers such as the MIT Open Documentary Lab. In Brazil, some studies have emerged in recent years, but the artistic production and academic research has not followed this promising scenario. This article presents insights on the Brazilian scene of the interactive documentary, oriented by the perspective of relational aesthetics and developed by the authors in a vast research project.
\end{abstract}

Keywords: interactive documentary, webdocumentary, interactivity.

Résumé: Au cours des dernières années, un nombre important de productions internationales de narrations interactives non-fictionnelles se sont développées. Il s'agit de médias numériques qui utilisent et explorent la transversalité des langages et des supports. Ces narrations se développent dans un territoire hybride, entre le reportage-web, le documentaire, l'art interactif, le netart, les jeux vidéo, l'installation. Elles ont été appelées webdocumentaire, documentaire interactif, living documentary. Ces œuvres ont été reconnues dans des festivals internationaux de documentaire, comme l'IDFA, et incorporées à la recherche universitaire par des centres de recherche de référence, tels que le MIT Open Documentary Lab. Au Brésil, certains travaux ont émergé ces dernières années, mais la production artistique et la recherche universitaire n'ont pas accompagné ce scénario prometteur. Cet article présente un aperçu de la scène brésilienne du documentaire interactif, guidée par la perspective de l'esthétique relationnelle, et développée par les auteurs dans un vaste projet de recherche sur le terrain.

Mots-clés: documentaire interactif, webdocumentaire, interactivité.

Eu quero mapear novos terrenos e não cartografar velhas fronteiras.

Marshall McLuhan

\title{
Cenas e cenários interativos
}

Já há alguns anos, o New York Times criou sua linha de interactive storytelling, ${ }^{l}$ se utilizando dos recursos interativos da web associados a formas de contar histórias que integram textos, vídeos, fotografias, gráficos.

\footnotetext{
${ }^{1}$ Exemplo de sua produção nesse sentido em 2013: http://www.nytimes.com/newsgraphics/2013/12/30/year-in-interactive-storytelling/?smid $=$ tw-nytimes.
} 
O jornal acompanhou assim outras iniciativas francesas e o já premiado Firestorm, do The Guardian. Esses trabalhos são exemplos da crescente gama de produções internacionais de narrativas interativas não ficcionais, que utilizam as novas tecnologias e mídias digitais e exploram a transversalidade de linguagens e plataformas. Essas produções esboçam apenas uma pequena parte de um amplo campo, incipiente e híbrido, que acontece na interseção entre documentário, vídeo digital, arte interativa, netart, games, instalação. As obras dessa campo e suas propostas, processos e ferramentas variam muito entre projetos como Prison Valley, La vie à sac, Le défi des bâtisseurs, Remembrance of things to understand.

Alguns centros internacionais de pesquisa - como o MIT Open Documentary Lab ou Digital Cultures Research Centre - e de realização como o National Film Board (NFB) - têm associado e denominado essa diversidade de obras como webdocumentários, ciberdocumentários, living documentary ou documentários interativos. Por trás de toda essa cena de obras interativas, há cenários propícios para suas realizações. Grande parte das obras foram incorporadas a estudos e festivais de documentário, onde já tiveram algum reconhecimento. Alguns festivais internacionais de cinema de prestígio criaram, inclusive, seus prêmios e mostras de obras interativas, como o Festival de Cannes e o Sundance, que criou um programa chamado de New Frontier Story Lab, a partir do envio da proposta de um documentário interativo chamado 18 days in Egypt. Alguns festivais de documentário também já criaram seus programas para obras interativas, como o Sheffield Doc Fest, na Inglaterra. Talvez o caso mais notório seja de um dos festivais mais reconhecidos de cinema documentário do mundo. O International Film Festival of Documentary (IDFA) de Amsterdã desenvolveu seu IDFA DocLab, que diz em sua apresentação: "The mission of IDFA DocLab is to showcase interactive documentaries and other new 
digital artforms that succesfully push the boundaries of documentary storytelling in the age of the interface."2

O desenvolvimento das narrativas interativas digitais tem sido bastante rápido e se concentrado na França, no Canadá e, mais recentemente, nos EUA e Reino Unido. Em 2010, o canal francês France 2 já era elogiado por sua ousadia ao criar ume série de webdocumentários. Em cinco anos, a situação evoluiu de tal forma que o National Film Board (NFB), no Canadá, principal realizador do mundo, já conta com mais de 40 títulos de projetos interativos, dentre os quais o premiado Highrise, out my Window.

A cena da nova produção de documentários interativos acontece sustentada por redes que apresentam pólos criativos fisicamente determinados em torno de Paris, Montreal/Toronto, Nova Iorque e Bristol/Londres. Esses locais concentram a produção das principais obras e, justamente, os principais centros de pesquisa, os principais canais e fontes de informação e os principais realizadores. Talvez isso aconteça porque, como apresenta um estudo do Observatoire du Documentaire (2013), do Canadá, os documentários interativos requerem novas ferramentas e formas de produção e distribuição, inclusive no processo de financiamento. Situados entre a produção audiovisual, o design e a programação, esses projetos precisam não apenas dos recursos, técnicas e conhecimentos dessas áreas, como de novas ferramentas, processos e habilidades técnicas e estéticas. São precisos novos arranjos produtivos de economia criativa e redes propulsoras de inovação tecnológica e desenvolvimento de experimentações estéticas e de linguagem. Esse quadro destaca a importância da cooperação, o diálogo e as redes entre realizadores, apoiadores, patrocinadores e centros de pesquisa, festivais e canais de informação sobre o tema.

${ }^{2}$ http://www.doclab.org/. 
$\mathrm{Na}$ França, entre os realizadores, encontramos algumas televisões e filmotecas públicas, com destaque para o canal franco-alemão Arte, que aposta fortemente nos documentários para web, às vezes com interseção com a produção para TV. A Arte estabelece convênios e coproduções com outras produtoras multimídias, como a Upian e a Honkytonk Films, que tem se destacado nos festivais e investe no desenvolvimento tecnológico do software Klynt, uma ferramenta de edição interativa dedicada a cineastas, fotógrafos e jornalistas ${ }^{3}$. Em Bristol, na Inglaterra, encontra-se Digital Cultures Research Centre, da University of West England, que realiza o $i$ Docs, o evento mais importante especificamente sobre documentários interativos no mundo. $\mathrm{O}$ evento é coordenado por pesquisadores e realizadores já reconhecidos no campo como Sandra Gaundenzi - uma das teóricas mais citadas em estudos sobre documentários interativos. Em Nova Iorque e arredores, o renomado Tribeca Film Institut (TFI) criou o programa TFI Interactive. E, por sua vez, nos Estados Unidos há o MIT Open Documentary $L A B$ que, entre suas atividades, desenvolveu talvez o maior banco de dados sobre documentários interativos, em parceria com o IDFA: a Docubase.

Talvez o exemplo mais significante, entretanto, seja o Canadá, um dos países pioneiros no desenvolvimento de tecnologias interativas aplicadas aos meios de comunicação, com uma forte tradição de inovação no cinema documentário como um todo. O NFB é reconhecido internacionalmente como um dos principais inovadores na criação de conteúdos audiovisuais interativos para a internet. Projetos como Highrise, Welcome to Pinepoint e Capturing Reality, premiados internacionalmente, são referências importantes para a criação atual. O Doc Toronto criou o docshift, que, entre outras coisas, organiza o Docshift Summit. Em Montreal,

\footnotetext{
${ }^{3}$ Uma série de softwears e plataformas têm sido desenvolvidos nesse sentido: como o Korsakow, por Florian Thalhofer e sua K-films; Klynt, pela Honkytonk; plataformas na web como o já extinto 3WDOC e as novas Conductr e Racontrl.
} 
três universidades (UdeM, UQM, Concordia Univerity) se destacam nas pesquisas sobre arte interativa e documentários e mantém o HexagramCIAM, um centro inter-universitário de artes midiáticas, além da escola L'INIS, que oferece regularmente formações em webdocumentário. Essas instituições de pesquisa e inovação, articuladas em rede com outras similares internacionais e com realizadores como NFB, criam um cenário fértil para a realização de uma série de obras que se destacam no cenário internacional, tanto no sentido de alcance das novas audiência via web, como no sentido de experimentações estéticas.

A produção brasileira de narrativas interativas para a internet e aplicativos não acompanha a cena desses principais pólos internacionais identificados, tanto no volume de produções como na interatividade das propostas. Em um primeiro momento de pesquisa, ainda entre 2010 e 2012 , já havíamos notado uma produção incipiente de narrativas interativas não ficcionais na web. Nesse sentido, se destacava o trabalho da produtora Cross Content, ${ }^{4}$ em São Paulo, liderada por Marcelo Bauer, que realizou trabalhos pioneiros como Filhos do tremor, lançado em 2010. Não havia, inicialmente, uma produção crítica e informativa em português na web. A produtora era responsável pelo único blog identificado que publicava, entre outros conteúdos sobre documentário em geral, informações sobre documentários interativos ${ }^{5}$. Também não havia sido identificado, até o momento, centros ou linhas de pesquisa focadas nas narrativas interativas digitais como objeto de pesquisa explícito, ou publicações acadêmicas. Algumas pesquisas isoladas foram encontradas (Ribas, 2003; Sacrini, 2004; Maia e al., 2009; Renó, 2006). Certamente não havia um terreno fértil que agregasse inovações tecnológicas e experimentações estéticas e de linguagem.

${ }^{4}$ http://www.crosscontent.com.br/. ${ }^{5} \mathrm{http}: / /$ webdocumentario.com.br/. 
Os cenários encontrados sinalizam tanto a insuficiência da produção brasileira, como o potencial que as narrativas interativas já apresentam nos pólos criativos identificados. Além disso, indicam a importância das redes e das inovações tecnológicas e estéticas para as novas produções e seus processos criativos. A partir do reconhecimento desse quadro que demos início a uma projeto de pesquisa-ação ${ }^{6}$ que buscasse um mapeamento crítico das produções brasileiras e das principais referências internacionais. Os cenários esboçados neste item apontam as referências para um estudo do caso brasileiro. O item a seguir explora as linhas gerais da perspectiva teórica orientadora do mapeamento e da pesquisa-ação, que vem sendo desenvolvidos a partir de uma estética relacional própria (Paz e Salles, 2013). Essas orientações e as diretrizes metodológicas da pesquisa, apresentadas no item III, são fundamentais para o recorte apresentado no item IV, que aponta as primeiras aproximações ao cenário brasileiro de documentários interativos.

\section{Uma Estética Relacional}

O campo das narrativas interativas digitais ainda está em formação, de maneira que a própria terminologia não está minimamente estabelecida ${ }^{7}$. Em geral, são designações que associam o suporte da internet ao gênero

\footnotetext{
${ }^{6}$ Como apresentado a seguir, a perspectiva da pesquisa-ação consiste, sumariamente, na articulação entre a pesquisa teórica e uma prática de intervenção. Na pesquisa-ação, os pesquisadores se inserem no fenômeno estudado e assumem papel de co-realizadores da ação estudada.

${ }^{7}$ Há um debate sobre definição do que caracteriza e vem a ser documentário interativo, webdocumentário ou living Documentary (Galloway et al., 2007; Gaundenzi, 2013a, 2013b;Gifreu, 2013). O webdocumentário tem sido visto como um documentário interativo que necessariamente tenha uma plataforma na web como vetor principal de realização da obra/processo. No entanto, os documentários interativos não se restringem ao suporte da internet. Um exemplo é Rider Spoke (2007), do coletivo britânico Blast Theory, um documentário interativo no qual o participante é convidado a fazer um passeio de bicicleta escutando uma gravação e parando em determinados lugares para gravar respostas às perguntas enviadas pelo dispositivo. Não há nenhum objeto a ser visto na internet, a obra existe apenas na experiência de quem sobe numa bicicleta e participa das atividades propostas.
} 
documentário e à interatividade, mas cada vez mais essa associação parece não dar conta da heterogeneidade das obras. O que parece certo é que o estatuto do espectador requer uma nova nomenclatura - como nas artes interativas em geral. Como afirma Louis-Claude Paquin (2006: 15; tradução livre): "Com as interfaces de manipulação direta, os espectadores tornam-se interatores. A interatividade é a relação que une as pessoas ao conteúdo. A interface é o dispositivo que permite o controle e o acesso ao conteúdo". Assim, consideraremos os documentários interativos como os projetos marcados por se constituírem como narrativas interativas não ficcionais que usam diferentes mídias e plataformas. Por enquanto, talvez apenas por estar neste estágio inicial, não há um formato estabelecido, os projetos precisam conceber seus próprios dispositivos em cada caso a partir do uso das diversas ferramentas. Ainda que alguns padrões se repitam, em muitos casos, os dispositivos de interação, as estratégias narrativas e os processos de produção configuram processos criativos singulares. Essa definição mais ampla é que foi a utilizada para o mapeamento do cenário brasileiro.

Alguns trabalhos internacionais já se estabeleceram como referências teóricas para se pensar a diversidade dos documentários interativos (Gifreu, 2013, 2014; Galloway et al., 2007; Gaudenzi, 2013a, 2013b). Gifreu (2013, 2014), por exemplo, faz uma proposta de classificação em função do conteúdo (temática), da experiência interativa e da plataforma que suporta a interface. Nesse sentido (Gifreu, 2013, 2014), destaca cinco categorias temáticas: ecologia e meio ambiente, guerras e conflitos, culturas urbanas, arte e difusão cultural, histórias pessoais. Em relação às plataformas, apresenta todo um conjunto (CD-DVD ROM, Instalação, TV/Cine, Web, Móvil e Multiplataforma), mas destaca o predomínio dos navegadores da web e aponta a televisão interativa como 
uma plataforma promissora ${ }^{8}$. A diversidade das plataformas utilizadas é considerada um fator chave da obra, por isso foi destacada no mapeamento brasileiro.

Outra característica fundamental de cada obra é a natureza da interatividade proposta. Gaudenzi (2013a) define quatro modos de interatividade do interator na obra: experimental, participativo, conversacional e hipertextual. Estes modos implicam o público em diferentes graus de participação. As possibilidades de intervenções criativas na participação do público é decrescente (do experimental ao hipertextual), sendo o modo experimental o que oferece maior margem de manobra ao interator. Há uma relação direta entre essas possibilidades e a imprevisibilidade do resultado: quanto maior a liberdade proporcionada pela interatividade, mais imprevisível será o resultado obtido. No caso da interatividade hipertextual, por exemplo, os caminhos a serem percorridos já estão previamente traçados, o interator pode passar de um ponto a outro mas não interfere no conteúdo da obra. Esses modos de interação não são exclusivos, frequentemente um mesmo documentário utiliza simultaneamente diferentes tipos de interatividade.

Um exemplo dessa coexistência de plataformas e formas de interatividade encontramos em Highrise, talvez a referência mais importante de documentário interativo. Highrise é na realidade um conjunto de documentários interativos sobre a questão das habitações verticais em grandes edifícios, comuns em cidades grandes por todo o mundo. Em Short history of HighRise, o interator pode apenas interagir de forma hipertextual pelos diversos conteúdos e mídias da história do projeto como um todo. O mesmo não acontece em One millionth tower, The thousand tower e Out my window. Em Highrise, Out my window, por exemplo, além de percorrer os

\footnotetext{
${ }^{8}$ Como aponta Gifreu (2014), a maioria dos projetos se concebem com uma lógica de múltiplas plataformas (Crossmedia) e mesclam diferentes gêneros e formatos (transmedia), mas, ainda que essas sejam componentes comuns nos documentário interativos, não são condição suficiente nem necessária para a caracterização de um projeto como documentário interativo.
} 
diferentes ambientes, o interator também pode submeter suas próprias imagens e textos sobre sua experiência em grandes prédios urbanos. Um guia pedagógico também é colocado à disposição do público, principalmente para que educadores possam utilizar o webdocumentário como uma ferramenta para trabalhar questões relacionadas à comunidade local. A obra não existe como um objeto fixo e o interator tem uma participação criativa na mesma.

Os trabalhos de Gaundenzi, Gifreu e outros, apresentam um glossário de referencias teóricas para um mapeamento dos documentários interativos. Inclusive alguns artigos e trabalhos de autores brasileiros ouescritos em português utilizam esses autores como referência (Amorim e Baldi, 2013; Bernardes, 2014; Levin, 2013; Paz e Salles, 2013). A partir dessas referêncais, podemos identificar a variação das propostas e temáticas. A forma de interatividade e experiência do usuário são muito diferentes entre projetos como One millionth tower, Walking the Edit ou Prison Valley. As estruturas narrativas e plataformas utilizadas de Hollow não condizem com as de Le défi des bâtisseurs. O processo de produção e recursos necessários para se fazer Fort McMoney são muitas vezes maiores que produções com software livre como Ceci n'est pas embres. No entanto, como aponta Massumi (2008), a proposta e discussão estética da interatividade precisa ir além da idéia do "You may Interact". A interação instaura um regime de poder que pode ser bastante tirânico. É nesse sentido que este projeto também busca inserir as reflexões em um contexto mais amplo, que não apenas traga as referências já existentes, mas desenvolve contribuições para os debates acadêmicos internacionais sobre as narrativas interativas não ficcionais.

Como já exploramos anteriormente, a interatividade transforma certas práticas de produção e recepção do cinema documentário de tal forma que exige uma reconsideração estética do mesmo. 
É necessário um esforço de redescrição criativa de um novo vocabulário de referências teóricas para interpretar as obras e potencializar suas possibilidades de realização. No sentido de tentar contribuir nesse processo, nos parece fértil buscar desenvolver uma perspectiva relacional, análoga à forma como Bourriaud (2009) compreende a arte contemporânea em geral, com seu caráter processual e comportamental, em função de noções interativas, convivenciais e relacionais. (Paz e Salles, 2013).

As reflexões nesse sentido precisam incorporar as contribuições teóricas do campo da criação artística e da tradição do documentário, em um contexto mais amplo das relações humanas, que fazemos a partir de autores como Vilém Flusser (2002a, 2002b, 2003, 2007, 2008). Nesse sentido, este ensaio faz parte de uma linha de investigação que reflete sobre a possibilidade de uma estética relacional para narrativas interativas focada nas formas de interações, encontros, relações e poéticas dos diferentes processos criativos. Como aponta Bourriaud (2009: 12), diante da padronização e previsibilidade das relações humanas, inseridas nas dinâmicas de espetacularização, mercantilização e profissionalização da vida cotidiana, as experimentações criativas podem fornecer possibilidades férteis para se criar novas formas de relação no mundo. E as obras não são mais vistas como um objeto pronto e acabado, mas como uma duração a ser experimentada, aberta para uma discussão ilimitada, que tem como tema central o estar-juntos, o encontro e a elaboração coletiva do sentido (2009: 21).

Nesse sentido, as contribuições de Vilém Flusser podem ser referências bastante úteis para se pensar os documentários interativos como uma forma específica de pensamento imagético, ${ }^{9}$ inserido em um novo

\footnotetext{
9 Para Flusser (2002/2007/2008), no universo da imagem técnica, o exercício crítico do pensamento não se restringe à escrita textual. As novas formas de pensamento precisam buscar configurações singulares de suas práticas que alternam recursos textuais e imagéticos de linguagem. O próprio Flusser desenvolveu a sua forma particular de pensamento imagético, afinal via os tradicionais textos filosóficos como algo decadente.
} 
regime de poder marcado pelos programas, aparelhos, funcionários, ferramentas e usuários. As contribuições flusserianas são elaborados desde uma perspectiva técnica que destaca a materialidade da comunicação. O que está em questão na obra de Flusser é a relação entre o homem e suas ferramentas, sobretudo aquelas que dizem respeito aos processos de comunicação a partir da disseminação das imagens técnicas. É nesse contexto onde surgem os documentários de dispositivo, ao conceberem e experimentarem diferentes formas de interações entre os elementos de realização do documentário como um processo criativo (Paz e Klinger, 2011). O que importa aqui é que esses documentários não narram uma história ou representam uma realidade pré existente às filmagens, eles produzem as realidades das quais falam a partir das interações eventuais da equipe com os participantes.

Os documentários interativos podem ser vistos como novas formas de documentários de dispositivo (Paz e Salles, 2013). A diferença fundamental é que a interação não acontece apenas nas filmagens, mas na própria recepção da obra enquanto processo. A recepção da obra é incorporada ao processo criativo através das diferentes formas de interatividade. Assim, o documentário interativo instaura um processo criativo coletivo, onde o espectador se transforma em interator e participa da criação mediada pelas interfaces das plataformas. As reflexões que se estabelecem vão no sentido de pensar de que forma os documentários interativos estabelecem seus processos criativos coletivos e interativos. Que relações de poder marcam suas interatividades? Que tipo de experiências e afetos disseminam? Obviamente, esses questionamentos requerem um trabalho de pesquisa muito mais extenso do que propõe este ensaio. O

Por um lado, o pensamento imagético traz a importância da experiência estética. Por outro, requer práticas de realização e recepção que se diferenciam bastante da escrita e leitura individual, solitária e silenciosa dos textos abstratos modernos. 
importante aqui é sinalizar um leque de questões que atravessa a realização da proposta de mapeamento a partir de uma estética relacional.

O exemplo de Highrise, mais uma vez, ilustra o quanto tais questões poderão estar presentes nesse novo campo. Highrise se tornou um departamento no National Film Board, um projeto guarda-chuva de produções interativas relacionadas com a temática de moradias em grande edifícios, como instalações, aplicativos para dispositivos móveis, filmes. O objetivo é explorar como o documentário interativo pode participar e ativar a inovação social mais do que apenas representá-la ou documentá-la. Em sintonia com a estética relacional apontada, o dispositivo interativo vislumbra que novas relações sejam criadas não apenas entre os interatores e a obra, mas também entre os interatores e seu meio social. ${ }^{10}$

Highrise ilustra como um documentário interativo pode ser visto como uma arte relacional (Bourriaud, 2009), que toma como horizonte teórico a esfera das relações humanas e seu contexto social e não a afirmação de um espaço simbólico autônomo. Vislumbra pequenas modificações, novas formas de relação no mundo a partir de seu processo criativo rizomático, múltiplo, indeterminado. Tenta mobilizar um esforço crítico que coloca em questão a vida em arranha-céus através de um engajamento criativo que imagina mudanças concretas, para o qual não há qualquer garantia e muita indeterminação. Highrise, One millionth tower foi desenvolvido com moradores do subúrbio de Toronto ao longo de anos. O projeto tem sua origem na relação desenvolvida com os moradores e em suas experiências de habitação. A diretora Katerina Cizek associou então os moradores a urbanistas, arquitetos, designers e programadores de

\footnotetext{
10 No próprio site encontramos a proposta do projeto: Over the years, Highrise will generate many projects, including mixed media, interactive documentaries, mobile productions, live presentations, installations and films. Collectively, the projects will both shape and realize the Highrise vision: to see how the documentary process can drive and participate in social innovation rather than just to document it; and to help re-invent what it means to be an urban species in the 21 st century.
} 
informática, para criar uma plataforma web ilustrando projetos de novas formas de habitação.

Assim, nos termos de Flusser, Highrise parece ser uma nova forma de pensamento imagético e nômade que se direciona como prática de experiências diferenciadas daquelas programadas por aparelhos. Tenta mobilizar um esforço crítico que coloca em questão a vida em arranha-céus através de um engajamento criativo que imagina mudanças concretas. Uma proposta como a de Highrise requer pelo menos uma estrutura e um processo produtivo complexo e custoso que está muito além da realidade brasileira. No cenário brasileiro, conforme apresentamos a seguir, não encontramos nenhuma obra com essa dimensão e alcance. Mesmo nos pólos criativos internacionais, projetos dessa dimensão representam apenas uma pequena parcela dos projetos de documentário interativo existentes. No entanto, no contexto da estética relacional apresentada, Highrise é a principal referência para se pensar as potencialidades e questionamentos por trás das correlações entre as possibilidades produtivas e as propostas éticas e estéticas das narrativas interativas.

\section{Uma bricolagem metodológica}

A metodologia da pesquisa do cenário brasileiro se justifica quando compreendida dentro do quadro de um projeto de pesquisa mais amplo, que compõe diversas abordagens metodológicas - uma prática definida nos campos das artes e da comunicação como uma bricolagem metodológica (Paquin, 2015). Esta composição nos permite articular diferentes metodologias para responder aos aspectos diversos das questões centrais de pesquisa e embasar ações, como apresentado a seguir. Nesse sentido, incorporamos princípios e orientações da perspectiva da pesquisa-ação e da cartografia, assim como técnicas de metodologia de estudo de caso. O estudo de caso nos permite definir o enquadramento do fenômeno 
observado, determinando, juntamente com a base teórica e conceitual da estética relacional, o recorte de observação dos dados, ou seja, o contorno do cenário brasileiro. Por outro lado, a cartografia, aliada aos princípios das metodologias de pesquisa-ação, orienta a observação participativa, a descrição dos projetos de narrativas interativas não ficcionais brasileiras e a concepção do projeto de intervenção.

A pesquisa-ação consiste, sumariamente, na articulação entre a pesquisa teórica e uma prática de intervenção. Para Desroche (apud Thiollent, 2006), grande parte das pesquisas sociais foram e ainda são elaboradas com o pressuposto de que o pesquisador se encontra fora do fenômeno que ele toma como objeto, onde sua ação está direcionada para a representação teórica daquele fenômeno. Na pesquisa-ação, os pesquisadores se inserem no fenômeno estudado e assumem esse lugar, como co-realizadores da ação estudada. A pesquisa-ação encontra eco na cartografia (Passos et al., 2009, 2014), que propõe o monitoramento e registro das transformações em um território presente, suas conexões e redes e a implicação do pesquisador nessa rede. Busca uma intervenção e sua validação acontece justamente em função dos efeitos e desdobramentos das ações. Importa se a pesquisa tem ou não potência para transformação da realidade. Por outro lado, faz parte da cartografia se afetar com o território, com o campo de pesquisa. Busca-se afetar e ser afetado, construir saberes de forma coletiva. Não é um método para se aplicado (Passos et al, 2009, 2014). Assim, entre pesquisa-ação e cartografia, a pesquisa buscar influenciar e ser influenciada pela realização de um projeto, onde autores e objetos de pesquisa se misturam.

As ações do projeto de pesquisa formam a plataforma digital Bug404, ${ }^{11}$ que busca incentivar o diálogo crítico e produtivo e fomenta a formação de parcerias e de uma rede sobre narrativas interativas não

\footnotetext{
${ }^{11}$ BUG404 é um website com mídias sociais através das quais se divulga e articula um rede sobre narrativas interativas no Brasil. www.bug404.net
} 
ficcionais. Como primeiras ações, procuramos realizar e divulgar um mapeamento das principais produções internacionais e das obras e realizadores nacionais. Esse mapeamento é voltado para a replicação criativa dos procedimentos interativos, estratégias narrativas, recursos técnicos. A pesquisa do projeto em geral se propõe como uma espécie de reflexão sobre os processos criativos, que articula as condicionantes produtivas (atores, procedimentos, técnicas, recursos, softwares e linguagens) às características estéticas da obra e suas implicações éticas, a partir da estética relacional esboçada anteriormente. É dentro desse quadro que se estrutura a pesquisa sobre o cenário brasileiro. O Bug404 tenta colaborar para a superação dos obstáculos ao desenvolvimento das narrativas interativas não ficcionais no Brasil identificados nos estudos de caso.

O estudo de caso é uma abordagem que visa observar o objeto de estudo em sua complexidade, através da consideração das interações com o meio no qual ele se insere. No caso desta pesquisa, o contexto do objeto de estudo é um aspecto central, pois um de nossos principais objetivos é justamente compreender o cenário atual brasileiro no campo do documentário interativo. A metodologia de estudo de caso nos permite então observar o fenômeno do desenvolvimento das narrativas interativas sem retirá-las de seu contexto, para em seguida compor uma imagem mais ampla do cenário nacional deste tipo de criação. Esta abordagem também nos permite evitar determinismos tecnológicos, pois ela propõe: “(...) une compréhension profonde des phénomènes, des processus les composant et des personnes y prenant part" (Gagnon, 2011: 2).

A primeira etapa de nossa abordagem foi a identificação dos casos, ou seja, identificar o maior numero possível de narrativas interativas não ficcionais realizadas no Brasil. Em razão da ausência de redes específicas de informação, da escassez de pesquisas acadêmicas sobre esta temática e do dinamismo destas mídias (muitas obras existem por apenas um ano, 
tornando-se inacessíveis posteriormente), acreditamos que esse levantamento inicial não abarque a totalidade dos casos, mas seja uma amostra suficiente para o desenvolvimento da pesquisa. As obras foram encontradas principalmente a partir de buscas e das citações nas diversas formas de publicação na internet. A maioria das obras possui um site especifico.

Este levantamento mais amplo foi feito com um recorte desenvolvido a partir dos trabalhos de Gifreu (2013), Bole e Mal (2014) e Gaudenzi (2013a), que identificaram as tendências internacionais da produção de narrativas interativas não ficcionais. Este recorte foi adequado e complementado pelas orientações das reflexões sobre uma estética relacional. Nesse sentido, selecionamos grupos de variáveis para uma primeira observação do cenário brasileiro atual de produção dos documentários interativos, através do estudo inicial das obras. Os grupos de variáveis são os seguintes:

- Suporte: meio de exibição da obra (internet, aplicativo, DVD).

- Metodologia de criação: o desenvolvimento da interatividade foi feito por um programador ou por software?

- Campo de atividade dos realizadores: áreas de origem e atuação dos autores e realizadores (jornalismo, artes plásticas, web designer).

- Experiência do interator: a forma de interatividade (hipertextual, participativa, geolocalizada) e de experiência (informativa, estética) propostas ao interator.

A partir deste primeiro trabalho mais amplo de levantamento, as principais tendências das narrativas interativas não ficcionais brasileiras foram identificadas. Passamos então para a segunda etapa do estudo de caso, onde um número menor de obras foi selecionado para ser observado com mais detalhes. Para cada uma das tendências encontradas dentro dos quatro grupos de variáveis, uma obra foi selecionada como exemplo-tipo. O critério para a seleção destas obras foi a disponibilidade de material sobre a 
criação. Assim, foram selecionadas as obras sobre as quais encontramos inicialmente uma quantidade maior de informações a respeito do processo criativo, das intenções dos autores e da metodologia de criação. O estudo de caso mais detalhado nos ofereceu uma compreensão um pouco mais clara dos principais problemas encontrados na realização de documentários interativos no Brasil, que funcionam como barreiras ao seu desenvolvimento.

\section{Cenário Brasil}

Nas publicações brasileiras recentes, o termo webdocumentário (ou web documentário) aparece pela primeira vez, precocemente, em 2002, no trabalho de conclusão do curso (TCC) de jornalismo na UFBA, Maracangalha.com, um web documentário sobre uma vila do recôncavo baiano, apresentado por Beatriz Ribas. A estudante realizou um webdocumentário e produziu um texto teórico sobre sua produção e sobre este campo emergente. Como a própria já apresentava: “A elaboração de um produto para a Web, que explora características do suporte digital como interatividade, hipertextualidade, multimídia, e memória, para a documentação jornalística da experiência passada, presente e futura de uma comunidade demonstrou a necessidade de definir melhor o conceito emergente de web documentário" (Ribas, 2003:1). Este webdocumentário está atualmente fora do ar (offline), destino muito comum entre os diversos webdocumentários identificados que foram realizados como TCC. Apesar dessas primeiras referências serem contemporâneas ao surgimento do formato do webdocumentário no contexto internacional, o cenário brasileiro não acompanhou o ritmo de produção e de pesquisa dos pólos criativos. Nesse sentido, já afirmavam Sangiovanni e Rocha (2007: 28): 
A falta de uma tradição no desenvolvimento de webdocumentários, causada pela recente aparição do gênero no cenário comunicacional, impõe, logo a princípio, uma limitação no número de trabalhos acadêmicos e teóricos em torno da discussão do formato e suas potencialidades. Limitados numericamente sim, mas não inexistentes.

Desde o trabalho de Ribas, encontramos na literatura científica brasileira algumas tentativas de definir o campo do webdocumentário (Sacrini, 2004; Reno, 2006, 2013; Sangiovanni e Rocha, 2007; Maia et al., 2009; Amorim e Baldi, 2013; Levin, 2013; Pereira e Moraes, 2013; Spinelli, 2013; Rodrigues, 2013; Vissotto, 2015). Nesse sentido, aliás, cabe ressaltar a iniciativa do periódico Doc On-Line ao lançar um número em 2013 com um dossiê sobre webdocumentário, contando com diversos artigos em língua portuguesa ${ }^{12}$. Apesar de escassa, entretanto, a produção bibliográfica foi um importante caminho para levantarmos as obras realizadas no Brasil e identificar o que já era esperado: a produção brasileira de obras em termos numéricos e na complexidade da interatividade proposta não acompanhava a cena dos pólos criativos.

Fizemos um levantamento de cinquenta e cinco obras que identificamos como narrativas interativas não ficcionais digitais, mesmo que elas não se auto-definissem como tal. Os critérios para a seleção das obras observadas seguem os princípios metodológicos do estudo de caso. Dessas obras, uma grande parte são websites ou instalações que contam histórias factuais apresentadas por vídeos curtos, textos e ilustrações, marcadas sobretudo pelo que Gaundenzi chamou de modo de interatividade hipertextual. Apenas alguns casos possibilitam uma interatividade mais participativa, que permita, por exemplo, o envio de conteúdos pelos interatores. É muito comum as obras estarem envolvidas com alguma questão social (chamadas de issue driven) e terem um propósito que se

\footnotetext{
${ }^{12} \mathrm{http}: / /$ www.doc.ubi.pt/index14.html.
} 
aproxima de uma postura ativista. Mas apesar destas primeiras considerações mais gerais, vale ressaltar que nosso foco neste trabalho é apontar as primeiras considerações sobre, como indicado na metodologia, as seguintes variáveis: suporte, metodologia de criação, o campo de atividades dos realizadores e a experiência do interator.

O primeiro aspecto que chama atenção na cena de documentários interativos brasileiros é o suporte de exibição das obras. Neste grupo de variáveis, quatro tipos de suporte foram identificados: website, aplicativo, instalação e DVD interativo. Um único exemplo de narrativa interativa não ficcional foi encontrado em DVD, que é o caso do projeto de Lucas Bambozzi, O Tempo não recuperado (2003). O suporte observado com mais frequência foi, destacadamente, o website, principalmente na forma de webdocumentários. Filhos do tremor, lançado em 2010, foi o primeiro realizado por uma produtora, a Cross Content. Do mesmo grupo, Rio de Janeiro - Autorretrato é um dos webdocumentários realizados que se destaca nesse início no campo tanto da pesquisa quanto da produção do webdocumentário brasileiro. Realizado por Marcelo Bauer, em 2011, esta obra permite ao interator, através de uma interatividade hipertextual, acessar vídeos e fotos de fotógrafos moradores do complexo da Maré, no Rio de Janeiro.

O webdocumentário é uma das principais tendências no campo das narrativas interativas não ficcionais não apenas no Brasil. Em geral, o termo webdocumentário se refere às narrativas interativas que usam como suporte apenas um website. Nesse sentido, além de Rio de Janeiro - Autorretrato, as produtoras Cross Content e DocTela, em São Paulo, se destacaram inicialmente por trabalhos como Filhos do tremor, Se eu demorar alguns meses e Webdoc Graffiti. Mas nem todos documentários interativos se limitam ao website, nem mesmo possuem, necessariamente, um website, seja como parte da obra ou como material de divulgação. Muitos se utilizam dos aplicativos para smartphones e/ou tablets. É para esses trabalhos que o 
termo documentário interativo passa a ser mais usado, embora essas obras se afastem da estética e daquilo que, tradicionalmente, se associa ao termo documentário.

O aplicativo é um dispositivo ainda pouco utilizado no meio das narrativas não ficcionais brasileiras. Apenas sete trabalhos utilizaram esse suporte. A MobContent, ${ }^{13}$ no Rio de Janeiro, se destaca com a realização do Polissonorum e o projeto em andamento Rio Antigo. O desenvolvimento de um aplicativo necessita um trabalho e habilidade de programação ainda menos difundida entre programadores e designers (principalmente se comparados com o de um website). E os gerenciadores de conteúdo para website, que dispensam o programador para a realização de websites, ainda não têm correspondentes a altura quando se trata de aplicativo móvel. O aplicativo torna-se assim uma opção de suporte com um custo superior aos outros, um fator que influencia bastante a produção brasileira em função de ainda não existir um mercado estabelecido voltado para as narrativas interativas. A grande maioria dos projetos foram auto-financiados, apenas alguns conseguiram recursos por editais.

Um exemplo promissor de narrativa não ficcional brasileira que utiliza o aplicativo é o projeto Som dos sinos (2015), de Márcia Mansur e Marina Thomé. Como se define: “Através da plataforma multimídia com navegação interativa, documentário de longa metragem, intervenção pública e aplicativo para dispositivos móveis, o Som dos Sinos estabelece canais de acesso ao imaginário ao mesmo tempo em que revela identidades culturais desta região do estado de Minas Gerais.” (Som dos sinos, Sobre, 2015 [site web]: sem pagina). Este projeto transmídia se desenvolve também em aplicativo, utiliza a geolocalização (GPS) do telefone celular e oferece "Um áudio-guia a céu aberto, que promove outros sentidos à experiência da visitação e laços afetivos através de uma cartografia de memórias,

\footnotetext{
${ }^{13}$ Www.mobcontent.com.br.
} 
ressignificando os sons dos sinos que, muitas vezes, já não se escutam mais do cotidiano local." (Som dos Sinos, Aplicativo, 2015 [site web]: sem página). A plataforma do webdocumentário está prestes a ser lançada, mas o projeto já aparenta ser o exemplo mais elaborado de documentário interativo brasileiro, no sentido da multiplicidade de ferramentas, plataformas e ações. O projeto conta ainda com mapeamento sonoro, envio de vídeo-cartas e intervenções itinerantes: "uma noite em cada uma das 9 cidades, com projeções de imagens e amplificação de paisagens sonoras, sobre trilha composta a partir dos sons dos sinos, entrevistas e outras sonoridades locais, em apresentações com conteúdo exclusivo de cada cidade." (Som dos Sinos, Itinerâncias, 2015 [site web]: sem página).

Além dos DVD, websites e aplicativos, consideramos algumas instalações com tecnologias digitais como trabalhos de narrativas interativas não ficcionais. Essa forma de exibição é utilizada principalmente na interseção dos campos das artes plásticas e das narrativas digitais. Artistas como Lucas Bambozzi, Fernando Velazquez e Giselle Beiguelman vêm criando instalações como os dispositivos exibidos no MASP (Museu de Arte de São Paulo), em 2011, na exposição 6 bilhões de outros (realizados por Lucas Bambozzi e Kika Nicolela, como parte do projeto 7 milliards d'autres, de Yann Arthus-Bertrand), para que o público explore de forma interativa histórias de imigrantes em São Paulo. A experiência dessas instalações é bastante diferente da experiência na internet, principalmente em relação ao espaço e à coletividade. Por exemplo, para visitar uma instalação, o interator deve se dirigir ao local onde se encontra o dispositivo de narrativa, com isso, a questão do espaço físico onde se encontra o interator ganha uma relevância que não existe na internet. Dessa mesma forma, a experiência de uma instalação se faz, na maioria das vezes, em público, e não em um espaço individualizado.

Vale ressaltar que desde a década de 1960 artistas brasileiros começaram a incorporar computadores e algoritmos às suas obras 
interativas. Como nota Priscila Arantes: “Já em 1969, Waldemar Cordeiro, um dos pioneiros, juntamente com o artista cinético Abraham Palatnik, na área de arte e tecnologia no Brasil, desenvolve As derivadas de uma imagem, em parceria com o Professor Giorgio Moscati, inaugurando as experimentações em computer art no país." (Arantes, 2005:55). A obra Your life, our movie (2008), realizada por Fernando Velazquez, é um exemplo recente interessante da apresentação de narrativas interativas na forma de instalações. Neste trabalho, a narrativa é construída a partir de palavras selecionadas pelo interator, que são em seguida processadas por um software (desenvolvido pela colaboração do artista com um programador), e servem como tags para a busca de imagens na rede social Flickr. Três imagens são exibidas lado a lado em sequência, compondo assim um tríptico de vídeos, criados a partir da associação entre interator, software e redes sociais. Paula Braga coloca alguns questionamentos levantados pela obra de Velazquez, principalmente sobre essa tríplice autoria da obra: “Quem é o autor da obra? O artista? O programador? Os três participadores iniciais? O coletivo que criou o repositório de imagens na Internet? A santíssima trindade desdobra-se em uma multiplicidade incontável nessa net art.” (Paula Braga, in: Fernando Velazquez, 2012 [site web]: sem página).

O segundo grupo de variáveis observadas do cenário brasileiro diz respeito à metodologia de criação. Neste momento da pesquisa, o aspecto que avaliamos desta variável se reduz à forma do desenvolvimento da interatividade: se esta foi desenvolvida por um programador ou se o realizador utilizou um software de desenvolvimento de narrativas interativas (Klynt, Korsakow, Conductr, Racontr, entre outros). A observação desta variável é importante pois a utilização de softwares permite que realizadores sem experiência em programação possam criar narrativas interativas com mais autonomia, sem dependerem da colaboração de um programador, o que reduz muito o custo de realização. A falta de familiaridade com os softwares, ferramentas tecnológicas que facilitam e diminuem os custos do 
desenvolvimento de narrativas interativas, é um freio ao crescimento do campo, como concluem Maia et al., em pesquisa de 2009 sobre o papel do webdocumentário no letramento digital: "No Brasil, grande parte da população se vê excluída dessas novas formas de comunicação e encontra dificuldade quando se depara com a situação de ter que utilizar computadores para realizar alguma atividade. Embora a questão econômica possa ser vista como responsável por esta exclusão, ela não pode ser considerada o único fator que a determina." O conceito de letramento digital é então uma forma de incluir novas camadas da população ao processo de desenvolvimento e experiência das narrativas interativas. Maia et al. também ressaltam o importante papel pedagógico do letramento digital: "Consideramos, no entanto, o letramento digital como um lugar a ser introduzido/explorado como forma de auxiliar a inclusão digital e como aprendizado que deve ser estimulado, sobretudo no ambiente educacional para a formação do estudante." (Maia et al, 2009: 2).

Os dados obtidos no mapeamento indicam que uma porcentagem pequena (14\%) das narrativas interativas não ficcionais brasileiras utilizou softwares especializados. Foram encontrados quatro tipos de softwares de narrativas interativas entre as produções brasileiras: Korsakow, Klynt, Managana, ThingLink. O software Korsakow, inicialmente gratuito e opensource, foi criado pelos artistas/pesquisadores Florian Thalhofer e Matt Soar. O software, que tem versão em português, foi utilizado, por exemplo, na criação do webdocumentário brasileiro Se eu demorar uns meses (2014), de Giovanni Francischelli e Lívia Perez. Na apresentação do webdocumentário há uma referência direta ao software Korsakow: "Se eu demorar uns meses é um K-Filme, ou seja, um filme desenvolvido em Korsakow. Tendo como fundamentos a interatividade e a não linearidade, K-filmes são uma superação da limitação técnica de filmes anteriores a era do computador". 
Pelo Laboratório de Desenvolvimento Social (LTDS) da COPPE, o projeto Roteiro dos Fortes, dirigido por André Paz, utilizou o Klynt para fazer um webdocumentário sobre as diferentes relações das fortificações no Rio de Janeiro com as comunidades de seus entornos, chamado Nós dos Fortes. Diferente do Korsakow, o Klynt é um software pago, mas com mais recursos gráficos. Esses softwares têm sido ferramentas bastante úteis na realização de oficinas de webdocumentário. No 26 Festival Internacional de Curtas de São Paulo, em agosto de 2015, André Paz e Julia Salles realizaram, por exemplo, uma oficina de webdocumentário fruto da parceria do BUG404 com a Associação Cultural Kinoforum, que utilizou o Klynt e possibilitou que, em cinco dias de oficina, fosse realizado um webdocumentário chamado Pedalei até aqui?, sobre cicloativismo na cidade de São Paulo. Essas atividades só puderam ser realizadas em função de um software que dispensa a atuação de um programador profissional.

No terceiro grupo de variáveis, foi observada uma grande diversidade no campo de atividade dos realizadores de narrativas interativas não ficcionais. Esta diversidade pode ser um fator que dificulte a organização de redes de informação, assim como de curso regulares, no campo das narrativas interativas não ficcionais. Ela demonstra uma forte tendência das narrativas interativas a serem interdisciplinares, trabalhando com elementos do audiovisual, do grafismo, da informática e outros campos, dependendo do projeto.

Uma das principais áreas de desenvolvimento das narrativas interativas não ficcionais é o jornalismo. Como observou Sandra Gaudenzi em entrevista ao documentário interativo Caixa-Preta (Paz e Salles, [entrevista em vídeo] 2015: sem página), o consumo de jornais se faz cada vez mais no formato digital, os jornalistas estão precisando se adaptar a este novo suporte que utiliza diferentes mídias e não apenas textos e ilustrações. Nós já havíamos notado acima que esta tendência também se verifica no cenário internacional, onde jornais e televisões como The Guardian, Le 
Monde, TV5, Arte e Radio Canada, vêm produzindo um grande numero de webdocumentários. No Brasil, a produção interativa jornalística se aproxima mais da infografia do que das narrativas interativas, como nos exemplos Líquido e Incerto e A Batalha de Belo Monte, ambos da Folha de S. Paulo. No entanto, algumas produções para a internet se destacam no campo das narrativas interativas do jornalismo brasileiro, como A História de Mim e Filhos da dor, publicados em 2014 e 2015 respectivamente, pelo Jornal do Comércio.

Muitos estudantes de jornalismo têm escolhido recentemente o formato do webdocumentário para apresentar seus trabalhos de conclusão de curso (TCC). É o caso, por exemplo de Até breve, Haiti! (UnB), Transgressões (PUC-PR), Um novo olhar - abuso sexual infantil e pedofilia (PUC-SP). Estudantes de disciplinas ligadas à área de informática também produziram TCC na forma de webdocumentários, como no caso de For Game, de alunos do Curso Sistemas e Mídias Digitais, da Universidade Federal do Ceará.

Alguns realizadores de narrativas interativas não ficcionais vêm da prática do documentário audiovisual. É o caso por exemplo de Giovanni Francischelli, diretor de Webdoc Graffitti e Se eu demorar uns meses, e sócio fundador da produtora Doctela, uma das poucas produtoras brasileiras a constituir uma seção especializada em webdocumentários. Campos de atuação mais ligados à tecnologia também foram observados entre os realizadores de narrativas interativas, principalmente nas áreas ligadas à web e às TIC (tecnologias de informação e comunicação). A produtora MobContent é um exemplo de pioneirismo no desenvolvimento de narrativas interativas com forte apelo tecnológico. Como é colocado em seu site: “A natureza dos projetos desenvolvidos por nós tem, em seu DNA, a exploração de novas tecnologias como Realidade Aumentada, Captura de Movimentos e Robótica. Com o uso dessas ferramentas o aspecto narrativo é potencializado.” (Mob Content, Sobre, 2014 [site web]: sem página) . 
Enfim, gostaríamos de mencionar outros dois campos de atuação observados entre realizadores de narrativas interativas não ficcionais brasileiras: a pesquisa acadêmica e as artes plásticas. Este último já foi abordado no contexto das instalações interativas. Quanto à pesquisa acadêmica, além dos trabalhos de estudantes (TCC), o webdocumentário Nós dos Fortes, realizado pelo LTDS (Laboratório de Tecnologia e Desenvolvimento Social da Coppe/UFRJ), aponta para o potencial já demonstrado da interseção do webdocumentário com projetos de pesquisa e extensão nos cenários internacionais dos pólos criativos destacados, sobretudo no Canadá. O LTDS trabalha há mais de vinte anos com projetos de pesquisa-ação e, nos últimos anos, tem incorporado as narrativas interativas como ferramenta. É este o caso do projeto Ilha Grande: cada praia, uma ilha; cada ilha, uma história, que conta através de um webdocumentário histórias da Ilha Grande, no litoral sul do estado do Rio de Janeiro. Esse webdocumentário é também um Guia de Turismo Comunitário, que visa empoderar as iniciativas de turismo de base comunitária na ilha, como pousadas, restaurantes, campings ou mesmo residências de nativos que hospedam turistas em casa.

O último grupo de variáveis observa a experiência do interator. Considerando a postura da estética relacional da qual parte esta pesquisa, o modo de interatividade e o tipo de experiência estética propostos pelo realizador são aspectos que determinam as características da própria obra, pois esta se constrói na relação com o público. Assim, o trabalho de Gaudenzi (2013a) sobre os modos de interatividade mencionado acima e a estética relacional de Bourriaud (2009) nos oferecem alguns parâmetros para avaliarmos os dados do cenário brasileiro. Nós constatamos que a experiência de interatividade proposta pelas narrativas estudadas é principalmente a hipertextualidade. Outras formas de interatividade ainda são pouco exploradas no cenário brasileiro. O campo das narrativas jornalísticas contribui em grande medida ao desenvolvimento deste tipo de 
experiência interativa. No entanto, algumas exceções podem ser destacadas. O modo de interatividade experiencial (geolocalizado) é utilizado no aplicativo Som dos Sinos. O modo participativo, por sua vez, pode ser encontrado no trabalho de André Deak, Mapas afetivos. Neste webdocumentário, o interator pode enviar depoimentos em vídeo sobre sua relação com lugares da cidade de São Paulo. O projeto, realizado pela Liquid Media Laab, se define com "uma narrativa transmídia que conta histórias de pessoas a partir dos lugares." (Mapas afetivos, 2014 [site web]: sem página).

Essas primeiras aproximações ao cenário brasileiro de narrativas interativas não ficcionais e digitais evidenciam que ainda não se estabeleceram redes sólidas de realizadores e críticos do campo do documentário interativo. A incipiente produção de obras, conteúdo critico e pesquisa acadêmica no campo das narrativas interativas brasileiras ainda não encontrou respaldo em centros de estudo, festivais, instituições de produção e redes de informação (online e offline). Faz-se necessário não só um trabalho de comunicação entre os principais atores deste campo (realizadores, pesquisadores, críticos e público), como de divulgação das referências internacionais, tanto no sentido das obras, processos produtivos, procedimentos e estratégias, como das discussões e propostas estéticas. Trata-se de construir um terreno fértil que agregue inovações tecnológicas e experimentações estéticas e de linguagem, o que requer a cooperação entre realizadores e centros de pesquisa, base de dados, festivais e canais de informação a respeito desse campo incipiente e promissor. Essa necessidade é ainda mais aguda neste momento inicial, onde cada projeto precisa conceber a especificidade de seus dispositivos de interação, pois ainda não há um gênero ou processo produtivo estabelecido, que possa simplesmente ser replicado. 


\section{Referências bibliográficas}

AMORIM, Pedro e BALDI, Vania (2013), "Ética e estética da representação no Web-documentário" in Cultura midiatica 6(11). Disponível em: http://www.ies.ufpb.br/ojs/index.php/cm/article/view/17546/10066.

ARANTES, Priscila (2005), “Arte e mídia no Brasil: perspectivas da estética digital" in ARS, 3(6), pp. 53-65.

BERNARDES, Fernanda (2014), “Webdocumentário e interação: compreendendo o papel do usuário em Fort McMoney" in Anais de 10 Interprograma de mestrados, São Paulo, Faculdade Casper Libero.

BOLE, Nicolas e MAL Cédric (2014), Le webdoc existe-t-il?, Paris: Le Blog Documentaire éditions.

BOURRIAUD, Nicolas (2009), Estética relacional, São Paulo: Martins Fontes.

CLARK,Tracy Boyer Clark (2011), Behind the scenes of NFB's One millionth tower. Disponível em:

http://innovativeinteractivity.com/2011/11/22/behind-the-scenesof-nfbs-one-millionth-tower/.

DESROCHE, Henri (2006), "Pesquisa-ação: dos projetos de autores aos projetos de atores e vice-versa" in THIOLLENT, Michel (org.). Pesquisa-ação e projeto cooperativo na perspectiva de Henri Desroche. São Carlos: EdUFSCar, pp. 33-68.

FLUSSER, Vilém (2002a), Filosofia da Caixa Preta: ensaios para uma futura filosofia da fotografia, Rio de Janeiro: Relume Dumará. (2002b), Writings, Minneapolis, MN: University of Minnesota Press. 
(2003), The Freedom of the Migrant: objections to nationalism, Urbana and Chicago: University of Illinois Press. (2007), O Mundo codificado: para uma filosofia do design e da comunicação, São Paulo: Cosac Naif.

(2008), O universo das imagens técnicas: elogio da superficialidade, São Paulo: Annablume.

GAGNON, Yves-C. (2011), L'étude de cas comme méthode de recherche, Québec: Presses de l'Université du Québec.

GALlOWAY, Dayna; MCALPINE, Kenneth B. e HARRIS, Paul. (2007), "From Michael Moore to JFK Reloaded: Towards a working model of interactive documentary" in Journal of Media Practice, 8(3), pp. 325-339.

GAUNDENZI, Sandra (2013a), The Living Documentary: from representing reality to co-creating reality in digital interactive documentary. Tese de Doutorado, Goldsmiths College, University of London. (2013b), "The interactive documentary as a living documentary" in Revista Doc On-line, n. 14, pp. 9-31. Disponível em: http://www.doc.ubi.pt/.

GIFREU, Arnau C. (2014), "El Documental interactivo en la estrategia de la multidifusión digital: evaluación del estado del arte en relación con la temática, las plataformas y la experiencia del usuario" in Revista TELOS (Cuadernos de Comunicación e Innovación), pp.1-11. (2013), El Documental Interactivo: evolución, caracterización y perspectivas de desarrollo. Barcelona: UOCPress.

(2010a), The interactive multimedia documentary: a proposed analysis model. Tese de Doutorado, Department of Communication, Pompeu Fabra University. 
(2010b), El Documental Interactivo: una propuesta de modelo de análisys. Proposta paraTese de Doutorado, Department of Communication, Pompeu Fabra University.

LEVIN, Tatiana (2013), “Do Documentário ao Webdoc - questões em jogo num cenário interativo" in Revista Doc On-line, n. 14, pp. 71-92. Disponível em: http://www.doc.ubi.pt/.

MAIA, Ravena Sena; FREIRE, Fernanda M. P. e HILDEBRAND, Hermes R. (2009), "Letramento Digital em Foco: Design de Interação na Construção de um Web-documentário", in Anais de XIV Congresso de Ciências da Comunicação na Região Sudeste, Rio de Janeiro, Intercom - Sociedade Brasileira de Estudos Interdisciplinares da Comunicação.

MASSUMI, Brian (2008), "The Thinking-feeling of What Happens: a semblance of a conversation", Inflexions 1.1 "How is researchcreation?”, Université de Montréal, Montréal. Disponível em: www.inflexions.org

OBSERVATOIRE DU DOCUMENTAIRE (2013), Documentary and New Digital Platforms: an ecosystem in transition, A Documentary Network's Study, Montréal.

PASSOS, E.; KASTRUP, V.; ESCÓSSIA, L. (org.) (2009). Pistas do método da cartografia: pesquisa-intervenção e produção de subjetividade. Porto Alegre: Sulina.

PASSOS, E; KASTRUP, V.; TEDESCO, S. (org.) (2014), Pistas do método da cartografia 2: a experiência da pesquisa e o plano comum, Porto Alegre: Sulina

PAQUIN, Louis-Claude (2006), Comprendre les médias interactifs, Québec: Isabelle Quentin Éditeur. (2015), Méthodologie de la recherche création. Disponível em http://lcpaquin.com/methoRC/. 
PAZ, André F. e KLINGER, Diana (2011), "Refracción fragmentada. Personajes, vivencias y dispositivos en las realidades de los documentales contemporáneos en Brasil" in Revista Inti. University of Conneticut, n. 60.

PAZ, André F. e SALLES, Julia (2015), Entrevista com Sandra Gaudenzi, Caixa-Preta [entrevista em vídeo]. Disponível em: http://bug404.net/caixa-preta/.

(2013), "Dispositivo, acaso e criatividade: por uma estética relacional do webdocumentário" in Revista Doc On-line, n. 14, Agosto de 2013, pp 33-69.

Disponível em: http://www.doc.ubi.pt/.

PEREIRA, Luiz P. F. e MORAES, Isabela C. R. (2013), "Cinema Documentário, novos meios e formas: sobre os deslocamentos provocados pelo webdocumentário Out of My Window”. Revista Doc On-line, n. 14, Agosto de 2013. Disponível em: http://www.doc.ubi.pt/.

RENÓ, Denis (2013), "Diversidade de modelos narrativos para Documentários transmídia" in Revista Doc On-line, n. 14, Agosto de 2013. Disponível em: http://www.doc.ubi.pt/. (2006), “Ciberdocumentarismo: tópicos para uma nova produção audiovisual” in Ciências e Cognição, 7, pp.128-134.

RIBAS, Beatriz (2003), "Contribuições para uma definição do conceito de Web Documentário" in MACHADO, Elias; PALACIOS, Marcos, Modelos de Jornalismo Digital, Salvador: Calandra. Disponível em: http://docplayer.com.br/4491679-Contribuicoes-para-umadefinicao-do-conceito-de-web-documentario.html

RODRIGUES, Pedro F. V. A. (2013), Processos narrativos e autoria em documentário interativo, Dissertação de Mestrado, Departamento de Comunicação e Arte, Universidade de Aveiro. 
SACRINI, Marcelo (2004), "Perspectivas do gênero documentário pela apropriação de elementos de linguagem da TV Digital Interativa", in BOCC-Biblioteca on-line de Ciências da Comunicação. Disponível em: http://www.bocc.ubi.pt/pag/sacrini-marcelo-docdigital-interativo.pdf

SANGIOVANNI, Ricardo F. e ROCHA, Vitor B. (2007), Bolívia: mídia, política e sociedade: Roteiro para um web-documentário, Monografia de conclusão de curso Comunicação Social, com habilitação em Jornalismo, Faculdade de Comunicação, Salvador: Universidade Federal da Bahia.

SPINELLI, Egle M. (2013), "Webdocumentário: implicações dos recursos tecnológicos digitais na composição estrutural e narrativa do formato" in Revista Comunicação Midiática, 8(2), pp. 169-183.

VISSOTTO, Izabel (2015), "Memória e interface no web documentário Le Défi Des Bâtisseur: o irrompimento do presente expandido" in Tematica, 11(1), pp. 99-111.

\section{Referências de projetos}

\section{Cenário mundial:}

18 days in Egypt

http://18daysinegypt.com/

Capturing Reality

http://films.nfb.ca/capturing-reality/

Ceci n'est pas embres

www.embres.ca

Do not track

https://donottrack-doc.com/en/ 
Firestorm

http://www.theguardian.com/world/interactive/2013/may/26/firestor m-bushfire-dunalley-holmes-family

Fort McMoney

WWW.fortmcmoney.com

Highrise

http://highrise.nfb.ca/shorthistory/

Hollow

www.hollowdocumentary.com

La Vie à Sac

http://www.lavieasac.com/

Le défi des bâtisseurs

www. cathedrale.arte.tv

Offshore

www.offshore-interactive.com

One millionth tower

http://highrise.nfb.ca/onemillionthtower/

Out my window

http://interactive.nfb.ca/\#/outmywindow

Prison Valley

www.prisonvalley.arte.tv

Remembrance of Things to Understand

www. webdoc.chrismarker.ca

Short history of HighRise

http://highrise.nfb.ca/tag/a-short-history-of-the-highrise/

Walking the edit

www.walking-the-edit.net

Welcome to Pinepoint

http://pinepoint.nfb.ca/\#/pinepoint 


\section{Cenário brasileiro:}

\section{6 bilhões de outros}

http://www.lucasbambozzi.net/projetosprojects/6-bilhoes-de-outros

\section{A Batalha de Belo Monte}

http://arte.folha.uol.com.br/especiais/2013/12/16/belo-monte/

A história de mim

http://especiais.jconline.ne10.uol.com.br/ahistoriademim/

Até breve, Haiti!

http://www.atebrevehaiti.com/\#capitulo1

Fernando Velazquez

http://www.blogart.com/BIO

Filhos da dor

http://especiais.jconline.ne10.uol.com.br/filhos-da-dor/

Filhos do tremor

http://www.webdocumentario.com.br/haiti/index.html

\section{For Game}

http://www2.virtual.ufc.br/forgame/

Ilha Grande: cada praia, uma ilha; cada ilha, uma estória

www.ilhagrande.website

Liquido e incerto

http://arte.folha.uol.com.br/ambiente/2014/09/15/crise-da-agua/

Mapas afetivos

http://www.mapasafetivos.com.br/

Nós dos Fortes

http://nosdoforte.net/

Pedalei até aqui?

www.bug404.net/pedalei 
Brasil, mostra a sua cara ...

Polissonorum

http://www.polissonorum.com/

Rio de Janeiro - Autorretrato

http://www.riodejaneiroautorretrato.com.br

Se eu demorar uns meses

http://doctela.com.br/se-eu-demorar-uns-meses/

Som dos sinos

http://www.somdossinos.com.br/\#!documentariointerativo/

O tempo não recuperado

http://www.lucasbambozzi.net/projetosprojects/o-tempo-nao-

recuperado

Transgressões

http://www.transgressoes.com.br/

Um novo olhar - Abuso Sexual Infantil e Pedofilia

http://www.webdocnovoolhar.com.br/cgi-sys/suspendedpage.cgi

Your life, our movie

http://www.blogart.com/Your-life-our-movie

Webdoc Graffiti

http://www.webdocgraffiti.com.br/videos 